\title{
Communication
}

\section{The Emergence of Klebsiella pneumoniae with Reduced Susceptibility against Third Generation Cephalosporins and Carbapenems in Lagos Hospitals, Nigeria}

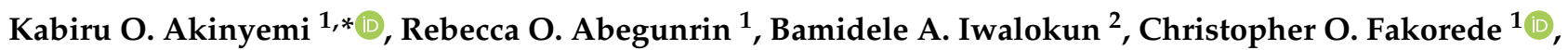 \\ Oliwia Makarewicz ${ }^{3}$, Heinrich Neubauer ${ }^{4}$, Mathias W. Pletz ${ }^{3}$ (i) and Gamal Wareth ${ }^{3,4,5, * \text { (i) }}$ \\ 1 Department of Microbiology, Lagos State University, Km 15, Badagry Expressway, P.O. Box 0001 Lasu Post \\ Office, Ojo, Lagos 102101, Nigeria; rabegunrin@gmail.com (R.O.A.); kriskorede@yahoo.co.uk (C.O.F.) \\ 2 Molecular Biology \& Biotechnology Department, Nigerian Institute of Medical Research, Yaba, \\ Lagos 100001, Nigeria; bamwal@yahoo.com \\ 3 Institute for Infectious Diseases and Infection Control, Jena University Hospital, Am Klinikum 1, \\ 07747 Jena, Germany; Oliwia.Makarewicz@med.uni-jena.de (O.M.); mathias.pletz@med.uni-jena.de (M.W.P.) \\ 4 Friedrich-Loeffler-Institut, Institute of Bacterial Infections and Zoonoses, Naumburger Str. 96a, \\ 07743 Jena, Germany; heinrich.neubauer@fli.de \\ 5 Faculty of Veterinary Medicine, Benha University, Moshtohor, Toukh 13736, Egypt \\ * Correspondence: kabiru.akinyemi@lasu.edu.ng or akinyemiko@yahoo.com (K.O.A.); \\ gamal.wareth@fli.de (G.W.)
}

\section{check for}

updates

Citation: Akinyemi, K.O.; Abegunrin, R.O.; Iwalokun, B.A.; Fakorede, C.O.; Makarewicz, O.; Neubauer, H.; Pletz, M.W.; Wareth, G. The Emergence of Klebsiella pneumoniae with Reduced Susceptibility against Third Generation Cephalosporins and Carbapenems in Lagos Hospitals, Nigeria. Antibiotics 2021, 10, 142. https://doi.org/10.3390/antibiotics 10020142

Received: 14 January 2021

Accepted: 29 January 2021

Published: 1 February 2021

Publisher's Note: MDPI stays neutral with regard to jurisdictional claims in published maps and institutional affiliations.

Copyright: (C) 2021 by the authors Licensee MDPI, Basel, Switzerland. This article is an open access article distributed under the terms and conditions of the Creative Commons Attribution (CC BY) license (https:// creativecommons.org/licenses/by/ $4.0 /)$.

\begin{abstract}
This study investigated the prevalence of Klebsiella (K.) pneumoniae isolates among clinical samples of patients in four medical centers in Lagos, Nigeria and the burden of extended-spectrum beta-lactamases (ESBL) and carbapenem-resistant K. pneumoniae (CRKP) strains. Different samples (stool, blood, urine, wound swabs and nasal swabs) from 127 patients with suspected Gram-negative infections based on on-site performed Gram-stain from four public hospitals between March and September 2015 were analyzed. K. pneumoniae was identified in 43 (34\%) patients. Resistance rates of these 43 strains according to the CLSI breakpoints were as followed: cotrimoxazole $(90.7 \%)$, cefuroxime $(74.4 \%)$, ofloxacin $(55.8 \%)$, ceftazidime $(46.5 \%)$, and cefixime $(35 \%)$. Three isolates (7\%) were resistant to imipenem. All isolates were susceptible to amoxicillin/clavulanic acid and nitrofurantoin. The prevalence of ESBL-producing, MDR and CRKP strains was $69.8 \%, 62.8 \%$, and $7.0 \%$, respectively. Of the ESBL-producing isolates, two K. pneumoniae isolates obtained from urine harbored both $b l a_{\mathrm{SHV}}$ and $b l a_{\mathrm{CTX}-\mathrm{M}-1}$, and a third isolate from urine harbored only the $b l a_{\mathrm{CTX}-\mathrm{M}-1}$. This study revealed the emergence of CRKP isolates and bla $a_{\mathrm{CTX}-\mathrm{M}-1}$ and bla $a_{\mathrm{SHV}}$ co-harboring K. pneumoniae strains in Lagos hospitals. The emergence of CRKP strains is an early warning signal for carbapenem antibiotics' prudent use with concern for their efficacies.
\end{abstract}

Keywords: Klebsiella pneumoniae; Carbapenem; ESBL; Emergence; Resistance; Nigeria

\section{Introduction}

Klebsiella (K.) pneumoniae is a Gram-negative opportunistic nosocomial bacterial pathogen. It is involved in several localized and disseminated hospital-acquired infections such as burns infections, sepsis, respiratory and gastrointestinal tract infections, urinary tract infections, pyogenic liver abscesses, and soft tissue and wound infection [1]. The emergence of carbapenem-resistant K. pneumoniae (CRKP) strains has become an ultimate challenge for public health globally due to their ability to disseminate rapidly in the hospital environment and their extended antibiotic resistance phenotypes [2]. In 2001, the first K. pneumoniae isolate with KPC-2 production was identified in the USA [3]. There are many mechanisms in K. pneumoniae that can drive carbapenem resistance; KPC-2 production is just one. A few years later, outbreaks began to appear in several countries. Nowadays, it is the most common carbapenemase-producing Enterobacterales (CPE), and is considered one of the most rapidly 
growing global threats due to the high mortality in hospital-associated infections [4]. In 2017, CRKP was classified among those global critical pathogens listed by WHO concerning discovering and developing new antibiotics.

In Nigeria, K. pneumoniae was among the most common causes of lower respiratory tract infections [5], neonatal septicemia, and bacteremia in children [6,7]. Antimicrobial susceptibility testing of 306 Gram-negative isolates from patients admitted to three teaching hospitals in South Western Nigeria in 2011 and 2013 revealed resistance to thirdgeneration cephalosporins in $92.2 \%$ and carbapenems in $52.6 \%$ of isolates [8]. Examination of 108 K. pneumoniae and 140 E.coli isolates from two tertiary hospitals in northwest Nigeria showed that $58 \%$ of the isolates were ESBL producers, while resistance to meropenem was observed in $40.3 \%$ of the isolate, and resistance to imipenem was observed in $36.6 \%$ [9]. However, the prescription and use of carbapenem antibiotics are still low, and there is a lack of recent information on multidrug resistance (MDR)-associated K. pneumoniae. The present study was conducted to investigate the prevalence of K. pneumoniae among clinical samples of patients in four medical centers in Lagos, Nigeria, and determine the burden of extended-spectrum beta-lactamase- (ESBL) and carbapenemase-producing strains.

\section{Results and Discussion}

Klebsiella pneumoniae was isolated from 34\% (43/127) of clinical samples analyzed in this study. K. pneumoniae was present in about half (55.8\%) of urine samples screened, an indication of etiological diagnosis in urinary tract infections, as no other bacterial pathogens were isolated. K. pneumoniae was detected in a quarter (23.3\%) of nasal swabs. In these cases, the link between K. pneumoniae isolation and infection cannot be considered sufficiently strong for an etiologic diagnosis because other Gram-positive bacterial agents could not be ruled. Three strains of K. pneumoniae (6.98\%) were isolated from three patients with soft tissue infection. Three strains $(6.98 \%)$ were isolated from three gastroenteritis cases, of which no other bacterial agents were detected (Table 1). K. pneumoniae was detected in samples of all the age groups studied, with young adults (15-30) being the age group most at the risk of K. pneumoniae-associated infections, occurring in $27.9 \%(12 / 43)$ followed by $25.6 \%(11 / 43)$ of patients in the age group 5-14 years (Table 1$)$. The prevalence of K. pneumoniae among patients suffered from urinary tract infections (UTIs) [10], suppurative otitis [11], and gut infection [12] is increasing worldwide.

In Nigeria, malaria is endemic. Three K. pneumoniae strains (6.98\%) were isolated from patients with concomitant Plasmodium falciparum infection. Co-infections of Enterobacterales with $P$. falciparum have been reported in some malaria-endemic African countries, including Nigeria, and were associated with increased severity [13]. Thus, such cases were also expected in this study, as it can be suggested that K. pneumoniae-associated bacteremia caused exacerbation of asymptomatic or silent malaria. Hence, this is the first report on K. pneumoniae-Plasmodium spp. co-infections in patients within Lagos hospitals in recent times.

Most isolates were resistant to cotrimoxazole $(90.7 \%)$, followed by cefuroxime $(74.4 \%)$, ofloxacin $(55.8 \%)$, ceftazidime $(46.5 \%)$, and cefixime $(35 \%)$. Three isolates $(7 \%)$ obtained from urine showed resistance to imipenem with a minimum inhibitory concentration (MIC) $>8 \mathrm{mg} / \mathrm{L}$. Resistance rates were lowest for gentamicin (4.7\%), imipenem (7\%), followed by ciprofloxacin $(28 \%)$ and no resistance $(0.0 \%)$ was recorded for amoxicillin/clavulanic acid and nitrofurantoin (Table 2). K. pneumoniae was among the predominant Gram-negative bacteria isolated in Sokoto, Northwest Nigeria, in 2019. It represented $14 \%$ of isolated bacteria, and most of the isolates were MDR and exhibited ESBL and carbapenemase activities [14]. Examination of $48 \mathrm{~K}$. pneumoniae strains isolated from Medical Institution in Oyo State, Nigeria, showed resistance in $88 \%$ of isolates to streptomycin and in $92 \%$ to cloxacillin, oxacillin, and colistin [15]. 
Table 1. Number and types of collected samples and K. pneumoniae positive isolates distributed across the subjects' age and sex used in the current study sampling hospitals.

\begin{tabular}{|c|c|c|c|c|c|c|c|}
\hline \multirow{2}{*}{\multicolumn{2}{|c|}{ Parameters }} & \multicolumn{6}{|c|}{ Types and Number of Collected Samples (Positive Sample) } \\
\hline & & Urine & Nasal Swab & Wound Swab & Feces & Blood & Total \\
\hline \multirow{5}{*}{ Hospitals } & CPHL & $9(6)$ & $11(4)$ & $7(1)$ & $9(1)$ & $6(1)$ & $42(13)$ \\
\hline & LASUTH & $10(5)$ & $9(3)$ & $5(1)$ & $2(0)$ & $7(2)$ & $33(11)$ \\
\hline & NIMR & $12(8)$ & $7(2)$ & $3(1)$ & $6(2)$ & $4(0)$ & $32(13)$ \\
\hline & IPHC & $6(5)$ & $3(1)$ & $5(0)$ & $3(0)$ & $3(0)$ & $20(6)$ \\
\hline & Total & $37(24)$ & $30(10)$ & $20(3)$ & $20(3)$ & $20(3)$ & $127(43)$ \\
\hline \multirow{6}{*}{ Age in Year } & $0-4$ & $6(3)$ & $3(1)$ & $2(0)$ & $3(0)$ & $1(0)$ & $15(4)$ \\
\hline & $5-14$ & $11(7)$ & $7(2)$ & $5(1)$ & $2(0)$ & $6(1)$ & 31 (11) \\
\hline & $15-30$ & $9(5)$ & $6(1)$ & $7(2)$ & $7(2)$ & $5(2)$ & $34(12)$ \\
\hline & $31-49$ & $5(4)$ & $8(3)$ & $4(0)$ & $5(1)$ & $5(0)$ & $27(8)$ \\
\hline & $\geq 50$ & $6(5)$ & $6(3)$ & $2(0)$ & $3(0)$ & $3(0)$ & $20(8)$ \\
\hline & Total & $37(24)$ & $30(10)$ & $20(3)$ & $20(3)$ & $20(3)$ & $127(43)$ \\
\hline \multirow{3}{*}{ Sex } & Male & $21(11)$ & $13(7)$ & $9(1)$ & $12(2)$ & $11(2)$ & $66(23)$ \\
\hline & Female & $16(13)$ & $17(3)$ & $11(2)$ & $8(1)$ & $9(1)$ & $61(20)$ \\
\hline & Total & $37(24)$ & $30(10)$ & $20(3)$ & $20(3)$ & $20(3)$ & $127(43)$ \\
\hline
\end{tabular}

The Central Public Health Laboratory (CPHL), Lagos State University Teaching Hospital (LSUTH), National Institute of Medical Research (NIMR), and Iba Primary Health Centre (IPHC).

Table 2. Antimicrobial susceptibility data and MIC values of $43 \mathrm{~K}$. pneumoniae strains collected from hospitals in Lagos.

\begin{tabular}{|c|c|c|c|c|c|c|}
\hline \multirow{2}{*}{ Antimicrobial Agent } & \multicolumn{2}{|c|}{ Standard Range } & \multicolumn{4}{|c|}{ Test Results } \\
\hline & $\mathrm{S} \leq(\mathrm{mg} / \mathrm{L})$ & $\mathrm{R} \geq(\mathrm{mg} / \mathrm{L})$ & $\mathrm{S}(\%)$ & $\mathrm{R}(\%)$ & MIC50 (mg/L) & MIC90 (mg/L) \\
\hline Ciprofloxacin & 0.25 & 0.5 & 72.1 & 27.9 & 0.25 & 1.5 \\
\hline Ofloxacin & 0.25 & 0.5 & 44.2 & 55.8 & 0.25 & 0.5 \\
\hline Gentamicin & 2 & 4 & 95.3 & 4.7 & 1.5 & 2.0 \\
\hline Cefixime & 1 & 2 & 65.1 & 34.9 & 1.0 & 1.5 \\
\hline Ceftazidime & 1 & 2 & 53.5 & 46.5 & 1.0 & 1.5 \\
\hline Cefuroxime & 8 & 16 & 25.6 & 74.4 & 16 & 16 \\
\hline Imipenem & 2 & 8 & 93.0 & 7.0 & 1.0 & 1.5 \\
\hline Cotrimozaxole & 2 & 4 & 9.3 & 90.7 & 4.0 & 16 \\
\hline Amoxicillin/Clavulanic Acid & 8 & 16 & 100 & 0.0 & 16 & 16 \\
\hline Nitrofurantoin & 8 & 16 & 100 & 0.0 & 16 & 16 \\
\hline
\end{tabular}

S: sensitive; R: resistance, MIC: minimum inhibitory concentration.

In this study, 27 (62.8\%) and $30(69.8 \%)$ K. pneumoniae were MDR and ESBL producing strains, respectively (Table 3). Previous epidemiological investigations have shown that MDR K. pneumoniae strains harboring ESBL genes exist in environmental sources [16] and are usually associated with nosocomial infections in Nigerian hospitals [17,18]. However, there are still few data available on the prevalence of $K$. pneumoniae in Nigerian hospitals. The published data are limited to regional studies and/or a limited number of samples [19]. Our results are comparable to Olalekan and colleagues' findings, who identified K. pneumoniae in 35.4\% of samples collected from four hospitals in Lagos between 2016-2018 [17], and Raji and co-workers, who found that K. pneumoniae represented $31.4 \%$ of strains collected during an assessment of the prevalence of drug resistance and ESBL among members of the family Enterobacterales at Lagos teaching hospital [18]. 
Table 3. Distribution of K. pneumoniae ESBL, MDR, and CAB in relation to clinical samples.

\begin{tabular}{cccccc}
\hline Samples & $\begin{array}{c}\text { Samples } \\
\text { No. (\%) }\end{array}$ & $\begin{array}{c}\text { Positive } \\
\text { No. (\%) }\end{array}$ & $\begin{array}{c}\text { ESBL+ } \\
\text { No. (\%) }\end{array}$ & $\begin{array}{c}\text { MDR+ } \\
\text { No. (\%) }\end{array}$ & $\begin{array}{c}\text { CAB+ } \\
\text { No. (\%) }\end{array}$ \\
\hline Urine & $37(29.2)$ & $24(55.8)$ & $16(66.7)$ & $17(70.8)$ & $3(12.5)$ \\
\hline Nasal swab & $30(23.7)$ & $10(23.3)$ & $7(70.0)$ & $4(40.0)$ & $0(0.00)$ \\
\hline Wound swab & $20(15.7)$ & $3(6.98)$ & $2(66.7)$ & $1(33.3)$ & $0(0.00)$ \\
\hline Feces & $20(15.7)$ & $3(6.98)$ & $2(66.7)$ & $2(66.7)$ & $0(0.00)$ \\
\hline Blood & $20(15.7)$ & $3(6.98)$ & $3(100)$ & $3(100)$ & $0(0.00)$ \\
\hline TOTAL & $127(100)$ & $43(34 \%)$ & $30(69.8)$ & $27(62.8)$ & $3(6.98)$ \\
\hline
\end{tabular}

ESBL: Extended Spectrum ß-lactamase; MDR: multidrug-resistant; CAB: carbapenem; (+): positive resistance.

In these MDR K. pneumoniae isolates, eleven resistance patterns were identified. The pattern ceftazidime/cefuroxime/ofloxacin/ciprofloxacin/cotrimoxazole (CAZ-CRX-OFLCIP-COT) was the most frequent one (Table 4). Two K. pneumoniae isolates from urine (U3 and U11) harbored both bla $a_{\mathrm{CTX}-\mathrm{M}-1}$ and bla $a_{\mathrm{SHV}}$, and one isolate (U19) harbored only $b a_{\mathrm{CTX}-\mathrm{M}-1}$. None of the tested strains contained the blaTEM. The emergence of resistance to imipenem is a new phenomenon, and the explanation is inconclusive because this drug is rarely used and relatively expensive. The prevalence of carbapenem resistance among clinical isolates of Enterobacterales was between $2.8 \%$ and $53.6 \%$ in a tertiary hospital in Lagos, Nigeria [20]. In 2019, most of K. pneumoniae strains isolated in Sokoto, Northwest Nigeria, exhibited ESBL and carbapenemase activities [14]. None of the three ESBL genes were detected in any of the three carbapenem-resistant K. pneumoniae isolates in our study. However, this may not ultimately rule out that these strains are non-carbapenemase producers, as they might be harboring other carbapenemase gene markers not screened in this study.

Table 4. Patterns of MDR to K. pneumoniae isolates recovered from clinical samples at hospitals in Lagos.

\begin{tabular}{cccc}
\hline Sample Types & No. of Isolates & Strains ID & Resistance Pattern \\
\hline Urine and Blood & 5 & U12, U36, B37, U38, U42 & CRX-OFL-COT \\
\hline Urine & 4 & U10, U23, U30, U43 & CAZ-CRX-OFL-COT \\
\hline Feces & 1 & F31 & CXM-OFL-CIP-COT \\
\hline Urine & 1 & U3, U11 & CRX-CXM-GEN-OFL-COT \\
\hline Urine & 2 & U13, U35 & CAZ-CRX-CXM-OFL-COT \\
\hline Urine & 2 & B40 CRX-CXM-IPM-COT \\
\hline Blood & 1 & W17, U19, N26 & CRX-CXM-OFL-CIP-COT \\
\hline Urine, Wound, and Nasal Swab & 3 & U18 & CAZ-CRX-OFL-CIP-COT-CXM-IPM \\
\hline Urine & 1 & U39, N4 & CAZ-OFL-CIP-COT \\
\hline Urine, Nasal Swab, Feces, and Blood & 5 & B33, N9, N16, F32, U41 & CAZ-CRX-OFL-CIP-COT \\
\hline Total & 27 & &
\end{tabular}

CAZ: ceftazidime $(30 \mu \mathrm{g})$; CRX: cefuroxine $(30 \mu \mathrm{g})$; GEN; gentamicin $(10 \mu \mathrm{g})$; CXM: cefixime $(5 \mu \mathrm{g})$; OFL: ofloxacin $(5 \mu \mathrm{g})$; AUG:

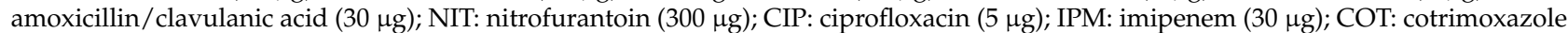
(25 $\mu \mathrm{g}) ; \mathrm{U}$ (urine), B (blood), F (feces), W (wound swab), N (nasal swab).

Only three genes were checked by PCR due to limited resources, which is a limitation of this study. Interestingly, the three CRKP strains were found in two different hospitals at a close distance of $20 \mathrm{~km}$, an indication of the emergence and circulation of CRKP in Lagos, Nigeria. The prevalence of carbapenem-resistance in 177 isolates of Enterobacterales was 22\% in South-West Nigeria in 2018; of them, 35.9\% $(n=14)$ were K. pneumoniae [21]. 
The emergence of ESBL due to bla $a_{\mathrm{CTX}}$ and bla $a_{\mathrm{SHV}}$ genes in K. pneumoniae has also been reported in other recent African studies. A high distribution of ESBL with the dominant bla $a_{\mathrm{CTX}-\mathrm{M}-1}$ gene marker was reported in Accra and Kumasi, Ghana [22]. A high prevalence of ESBL-producing K. pneumoniae in clinical isolates was reported in Côte d'Ivoire [23]. Strains harboring $b l a_{\mathrm{CTX}-\mathrm{M}-15}$ and $b l a_{\mathrm{SHV}-134}$ were isolated from pig and abattoir workers in Cameroon [24]. Carbapenem resistance is emerging in Africa, despite its not being routinely used due to high cost [25]. New antibiotics and new strategies are required to mitigate this increasing threat.

\section{Materials and Methods}

\subsection{Study Population, Case Definition, Sample Collection and Bacteriology}

The prevalence and burden of ESBL and CRKP strains were investigated, involving 127 patients with various types of infections admitted to four public Lagos hospitals between March and September 2015. The Central Public Health Laboratory (CPHL), Lagos State University Teaching Hospital (LSUTH), National Institute of Medical Research (NIMR), and Iba Primary Health Centre (IPHC) contributed 42, 33, 32, and 20 samples, respectively. The institutional review boards of Lagos State University and the Nigerian Institute of Medical Research approved the study and the ethical approval with a code [Ref. No. LREC 06/10/1071] was obtained. Moreover, the consent of the patients was sought. Data of the patients, including age and sex, were noted. In total, 37 urine samples, 30 nasal swabs, and 20 wound swabs were aseptically collected from patients diagnosed with urinary tract infections, otitis media and pneumonia, and soft tissue abscesses. Additionally, 20 fresh feces samples were collected from patients with gastroenteritis, and $4 \mathrm{~mL}$ blood was collected from another 20 patients suffering from pyrexia of unknown origin (PUO). All blood samples from PUO patients were subjected to the thick-blood smear technique to detect the malaria parasite (Plasmodium spp.). Bacterial culture of all samples was done on brain heart infusion (BHI) and Macconkey agar (Oxoid, UK), and plates were incubated at $37^{\circ} \mathrm{C}$ overnight under aerobic conditions. The lactose fermenting discrete colonies were subjected to biochemical identification, according to Crown and Steel 1993 [26]. Colonies biochemically confirmed as Klebsiella spp. were subjected to the MICROBACT 24E identification system (Oxoid, UK).

\subsection{Antimicrobial Susceptibility Testing (AST)}

All confirmed K. pneumoniae strains were tested against ten antibiotics by both disc diffusion and microdilution methods according to the CLSI guidelines [27]. The following antibiotic discs were used: cotrimoxazole (COT) $(25 \mu \mathrm{g})$, ciprofloxacin (CIP) $(5 \mu \mathrm{g})$, ofloxacin (OFL) $(5 \mu \mathrm{g})$, gentamicin (GEN) $(10 \mu \mathrm{g})$, cefixime (CXM) $(5 \mu \mathrm{g})$, amoxicillin/clavulanic acid (AMC) $(30 \mu \mathrm{g})$, cefuroxime (CRX) $(30 \mu \mathrm{g})$, ceftazidime (CAZ) $(30 \mu \mathrm{g})$, imipenem (IMP) $(30 \mu \mathrm{g})$, and nitrofurantoin (NIT) $(300 \mu \mathrm{g})$ (Oxoid, UK). The inhibition zones' diameters were measured with a ruler and compared with a zone-interpretation chart. The microdilution test was performed with the same set of antibiotics for consistency (Sigma, Deisenhofen, Germany) following the manufacturer's instructions. In this study, resistance was defined for isolates exhibiting intermediate resistance and resistance. The multidrugresistant (MDR) phenotype was defined as acquired non-susceptibility to at least one agent in three or more antimicrobial categories [28].

\subsection{Screening of Extended-Spectrum Beta-Lactamase (ESBL)}

All isolates that exhibited reduced susceptibility and resistance to third-generation cephalosporin were screened for ESBL production using the double disc synergy test (DDST). This was done by placing the 3GC antibiotics, i.e., ceftazidime (30 $\mu \mathrm{g})$ and ceftriaxone $(30 \mu \mathrm{g})$, at a distance of $15 \mathrm{~mm}$ (center to center) from $30 \mu \mathrm{g}$ amoxicillin/clavulanic acid (20 $\mu \mathrm{g}$ amoxicillin and $10 \mu \mathrm{g}$ clavulanic acid) using CLSI interpretation guidelines [27]. Detection of carbapenemase enzyme activity was done following the modified Hodge test (MHT) as described by Landman and colleagues [29]. For three ESBL gene makers, the 


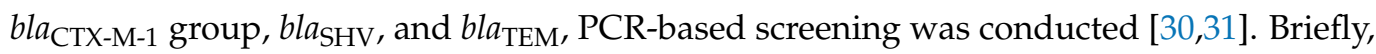
genomic DNA was extracted by the Tris-EDTA boiling extraction method [32], and the concentration and purity of DNA were determined spectrophotometrically (BIO-RAD Smart Spec 3000; Hercules, CA, USA). The detection of $\beta$-lactamase-encoding genes carried out using multiplex polymerase chain reaction (PCR) with primers that correspond to conserved regions of $b l a_{\mathrm{TEM}}, b l a_{\mathrm{SHV}}$, and $b l a_{\mathrm{CTX}} \mathrm{M}$-type genes. The primers were synthesized and supplied by Promega Corp, Germany. Each PCR reaction was done in a $20 \mu \mathrm{L}$ volume, comprising $1 \times$ PCR buffer ( $\mathrm{pH} 8.3$ ), $1.5 \mathrm{mM}$ of $\mathrm{MgCl}_{2}, 200 \mathrm{nM}$ each of the deoxynucleotide triphosphates (dNTPs), 40 picomoles each of the forward primer and reverse primers indicated in Table 5. One microliter $(1 \mu \mathrm{L})$ each of the genomic DNA templates $(\sim 100 \mathrm{ng})$ and 1.25 U of Taq polymerase (Promega, Germany) were used. The PCR program consisted of an initial denaturation step at $94{ }^{\circ} \mathrm{C}$ for $3 \mathrm{~min}$, followed by 25 cycles of DNA denaturation at $94{ }^{\circ} \mathrm{C}$ for $30 \mathrm{~s}$, primer annealing at $54{ }^{\circ} \mathrm{C}$ for $30 \mathrm{~s}$, and primer extension at $72{ }^{\circ} \mathrm{C}$ for $1 \mathrm{~min}$. After the last cycle, a final extension step at $72{ }^{\circ} \mathrm{C}$ for $7 \mathrm{~min}$ was applied. Five-microliter aliquots of PCR products were analyzed by gel electrophoresis with $2 \%$ agarose (Sigma-Aldrich, USA). Gels were stained with ethidium bromide at $0.5 \mu \mathrm{g} / \mathrm{mL}$ and visualized by UV transilluminator. A 100 bp DNA ladder (Fermentas, Burlington, ON, Canada) was used as a marker to extrapolate the $190 \mathrm{bp} \mathrm{PCR} \mathrm{product.} \mathrm{The} \mathrm{PCR} \mathrm{reaction}$ was done using a TC-312 thermal cycler (Techne, Amsterdam, The Netherlands).

Table 5. The primer sequences used for amplification of bla genes.

\begin{tabular}{|c|c|c|c|c|}
\hline Target & Primer & Primer Sequence $\left(5^{\prime}-3^{\prime}\right)$ & Product Size (bp) & Ref. \\
\hline \multirow{2}{*}{$b l a_{\mathrm{TEM}}$} & TEM-F & TCCGCTCATGAGACAATAACC & \multirow[t]{2}{*}{931} & \multirow{2}{*}{ [30] } \\
\hline & TEM-R & TTGGTCTGACAGTTACCAATGC & & \\
\hline \multirow{2}{*}{$b l a_{\mathrm{SHV}}$} & SHV-F & TGGTTATGCGTTATATTCGCC & \multirow[t]{2}{*}{868} & \multirow{2}{*}{ [31] } \\
\hline & SHV-R & GGTTAGCGTTGCCAGTGCT & & \\
\hline \multirow{2}{*}{$b l a_{\mathrm{CTX}} \mathrm{M}$} & CTX-F & TCTTCCAGAATAAGGAATCCC & \multirow[t]{2}{*}{909} & \multirow{2}{*}{ [30] } \\
\hline & CTX-R & CCGTTTCCGCTATTACAAAC & & \\
\hline
\end{tabular}

\section{Conclusions}

In conclusion, this study revealed the emergence and dissemination of carbapenemresistant $K$. pneumoniae isolates and $b a_{\mathrm{CTX}-\mathrm{M}-1}$ group and $b_{\mathrm{SHV}}$ co-harboring K. pneumoniae strains in Lagos. This study is limited by using a PCR screening tool that could only detect $b l a_{\mathrm{CTX}} \mathrm{M}-1, b l a_{\mathrm{SHV}}$ and $b l a_{\mathrm{TEM}}$. CRKP is emerging in Nigeria, despite carbapenem compounds not being routinely used in the health care system due to their high cost. New antibiotics and new strategies are needed to mitigate this increasing threat. A comprehensive study on the real situation on carbapenemase-producing K. pneumoniae in Lagos using advanced molecular typing tools to assess the diversity and clonal relatedness of the strains is required to better monitor and understand the spread of MDR K. pneumoniae in this region.

Author Contributions: K.O.A. conceived the study and designed the study protocol; R.O.A. and C.O.F. carried out the literature search and antimicrobial susceptibility testing; K.O.A. and B.A.I. performed molecular analysis, organized, integrated all data and carried out the investigation. K.O.A., R.O.A., and G.W. interpreted data and drafted the manuscript; K.O.A., O.M., M.W.P., H.N., and G.W. critically revised the manuscript for intellectual content. All authors read and approved the final manuscript. K.O.A. is a guarantor of the paper.

Funding: LASU and NIMR supported this work through provisions of consumables and the team's joint efforts.

Institutional Review Board Statement: The institutional review boards of Lagos State University and the Nigerian Institute of Medical Research approved the study and the ethical code [Ref. No. LREC 06/10/1071] was obtained.

Informed Consent Statement: The consent of the patients was sought. 


\section{Data Availability Statement: Not applicable.}

Acknowledgments: We are grateful to the Department of Microbiology staff and both the management of Lagos State University (LASU) and the Nigerian Institute of Medical Research (NIMR) for providing consumables and technical support, respectively. Part of this study's abstract was presented at the American Society for Tropical Medicine and Hygiene. It was published online in the American Journal of Tropical Medicine and Hygiene.

Conflicts of Interest: The authors declare no conflict of interest.

\section{References}

1. Ranjbar, R.; Fatahian Kelishadrokhi, A.; Chehelgerdi, M. Molecular characterization, serotypes and phenotypic and genotypic evaluation of antibiotic resistance of the Klebsiella pneumoniae strains isolated from different types of hospital-acquired infections. Infect. Drug Resist. 2019, 12, 603-611. [CrossRef] [PubMed]

2. Rossolini, G.M. Extensively drug-resistant carbapenemase-producing Enterobacteriaceae: An emerging challenge for clinicians and healthcare systems. J. Intern. Med. 2015, 277, 528-531. [CrossRef]

3. Yigit, H.; Queenan, A.M.; Anderson, G.J.; Domenech-Sanchez, A.; Biddle, J.W.; Steward, C.D.; Alberti, S.; Bush, K.; Tenover, F.C. Novel carbapenem-hydrolyzing beta-lactamase, KPC-1, from a carbapenem-resistant strain of Klebsiella pneumoniae. Antimicrob. Agents Chemother. 2001, 45, 1151-1161. [CrossRef]

4. Brink, A.J. Epidemiology of carbapenem-resistant Gram-negative infections globally. Curr. Opin. Infect. Dis. 2019, 32, 609-616. [CrossRef]

5. Uzoamaka, M.; Ngozi, O.; Johnbull, O.S.; Martin, O. Bacterial Etiology of lower respiratory tract infections and their antimicrobial susceptibility. Am. J. Med. Sci. 2017, 354, 471-475. [CrossRef]

6. Brown, B.; Dada-Adegbola, H.; Trippe, C.; Olopade, O. Prevalence and etiology of bacteremia in febrile children with sickle cell disease at a Nigeria tertiary hospital. Mediterr. J. Hematol. Infect. Dis. 2017, 9, e2017039. [CrossRef] [PubMed]

7. Akindolire, A.E.; Tongo, O.; Dada-Adegbola, H.; Akinyinka, O. Etiology of early-onset septicemia among neonates at the University College Hospital, Ibadan, Nigeria. J. Infect. Dev. Ctries 2016, 10, 1338-1344. [CrossRef] [PubMed]

8. Ogbolu, D.O.; Piddock, L.J.V.; Webber, M.A. Opening Pandora's box: High-level resistance to antibiotics of last resort in Gram-negative bacteria from Nigeria. J. Glob. Antimicrob. Resist. 2020, 21, 211-217. [CrossRef] [PubMed]

9. Ibrahim, Y.; Sani, Y.; Saleh, Q.; Saleh, A.; Hakeem, G. Phenotypic detection of extended-spectrum beta-lactamase and carbapenemase co-producing clinical isolates from two tertiary hospitals in Kano, northwest Nigeria. Ethiop. J. Health Sci. 2017, 27, 3-10. [CrossRef]

10. Vachvanichsanong, P.; McNeil, E.B.; Dissaneewate, P. Extended-spectrum beta-lactamase Escherichia coli and Klebsiella pneumoniae urinary tract infections. Epidemiol. Infect. 2020, 149, e12. [CrossRef]

11. Sun, R.; Zhang, H.; Xu, Y.; Zhu, H.; Yu, X.; Xu, J. Community-acquired Klebsiella pneumoniae central nervous system infection after acute suppurative otitis. IDCases 2021, 23, e01016. [CrossRef]

12. Antony, S.; Ravichandran, K.; Kanungo, R. Multidrug-resistant Enterobacteriaceae colonising the gut of adult rural population in South India. Indian J. Med. Microbiol. 2018, 36, 488-493. [CrossRef] [PubMed]

13. Akinyemi, K.O.; Bamiro, B.S.; Coker, A.O. Salmonellosis in Lagos, Nigeria: Incidence of Plasmodium falciparum-associated co-infection, patterns of antimicrobial resistance, and emergence of reduced susceptibility to fluoroquinolones. J. Health Popul. Nutr. 2007, 25, 351-358. [PubMed]

14. Olowo-Okere, A.; Ibrahim, Y.K.E.; Nabti, L.Z.; Olayinka, B.O. High prevalence of multidrug-resistant Gram-negative bacterial infections in Northwest Nigeria. Germs 2020, 10, 310-321. [CrossRef]

15. Ayandele, A.A.; Oladipo, E.K.; Oyebisi, O.; Kaka, M.O. Prevalence of multi-antibiotic resistant Escherichia coli and Klebsiella species obtained from a tertiary medical institution in Oyo State, Nigeria. Qatar Med. J. 2020, 2020, 9. [CrossRef]

16. Obasi, A.; Nwachukwu, S.; Ugoji, E.; Kohler, C.; Gohler, A.; Balau, V.; Pfeifer, Y.; Steinmetz, I. Extended-spectrum betalactamase-producing Klebsiella pneumoniae from pharmaceutical wastewaters in South-Western Nigeria. Microb. Drug Resist. 2017, 23, 1013-1018. [CrossRef] [PubMed]

17. Olalekan, A.; Onwugamba, F.; Iwalokun, B.; Mellmann, A.; Becker, K.; Schaumburg, F. High proportion of carbapenemaseproducing Escherichia coli and Klebsiella pneumoniae among extended-spectrum beta-lactamase producers in Nigerian hospitals. J. Glob. Antimicrob. Resist. 2019. [CrossRef]

18. Raji, M.A.; Jamal, W.; Ojemhen, O.; Rotimi, V.O. Point-surveillance of antibiotic resistance in Enterobacteriaceae isolates from patients in a Lagos teaching hospital, Nigeria. J. Infect. Public Health 2013, 6, 431-437. [CrossRef]

19. Hertz, F.B.; Jansaker, F.; Okon, K.O.; Abdulmumin, I.S.; Onah, J.O.; Ladan, J.; Knudsen, J.D. ESBL-production in Escherichia coli and Klebsiella pneumoniae isolates from Nigeria. MicrobiologyOpen 2019, 8, e00816. [CrossRef]

20. Oduyebo, O.O.; Falayi, O.M.; Oshun, P.; Ettu, A.O. Phenotypic determination of carbapenemase-producing Enterobacteriaceae isolates from clinical specimens at a tertiary hospital in Lagos, Nigeria. Trop. J. Pharm. Res. 2015, 22, 223-227. [CrossRef]

21. Adesanya, O.A.; Igwe, H.A. Carbapenem-resistant Enterobacteriaceae (CRE) and Gram-negative bacterial infections in south-west Nigeria: A retrospective epidemiological surveillance study. AIMS Public Health 2020, 7, 804-815. [CrossRef] [PubMed] 
22. Falagas, M.E.; Karageorgopoulos, D.E.; Nordmann, P. Therapeutic options for infections with Enterobacteriaceae producing carbapenem-hydrolyzing enzymes. Future Microbiol. 2011, 6, 653-666. [CrossRef] [PubMed]

23. Muller-Schulte, E.; Tuo, M.N.; Akoua-Koffi, C.; Schaumburg, F.; Becker, S.L. High prevalence of ESBL-producing Klebsiella pneumoniae in clinical samples from central Cote d'Ivoire. Int. J. Infect. Dis. 2019, 91, 207-209. [CrossRef]

24. Founou, L.L.; Founou, R.C.; Allam, M.; Ismail, A.; Djoko, C.F.; Essack, S.Y. Genome sequencing of extended-spectrum betalactamase (ESBL)-producing Klebsiella pneumoniae isolated from pigs and abattoir workers in Cameroon. Front. Microbiol. 2018, 9, 188. [CrossRef]

25. Njeru, J. Emerging carbapenem resistance in ESKAPE organisms in sub-Saharan Africa (SSA) and the way forward. Ger. J. Microbiol. 2021, 1. [CrossRef]

26. Phillips, I. Cowan and Steel's manual for the identification of medical bacteria. J. Clin. Pathol. 1993, 46, 975. [CrossRef]

27. CLSI (Clinical and Laboratory Standards Institute). Performance Standards for Antimicrobial Susceptibility Testing; Nineteenth Informational Supplement; CLSI: Annapolis Junction, MD, USA, 2011.

28. Magiorakos, A.P.; Srinivasan, A.; Carey, R.B.; Carmeli, Y.; Falagas, M.E.; Giske, C.G.; Harbarth, S.; Hindler, J.F.; Kahlmeter, G.; Olsson-Liljequist, B.; et al. Multidrug-resistant, extensively drug-resistant and pan drug-resistant bacteria: An international expert proposal for interim standard definitions for acquired resistance. Clin. Microbiol. Infect. 2012, 18, 268-281. [CrossRef] [PubMed]

29. Landman, D.; Salvani, J.K.; Bratu, S.; Quale, J. Evaluation of techniques for detection of carbapenem-resistant Klebsiella pneumoniae in stool surveillance cultures. J. Clin. Microbiol. 2005, 43, 5639-5641. [CrossRef]

30. Sturenburg, E.; Kuhn, A.; Mack, D.; Laufs, R. A novel extended-spectrum beta-lactamase CTX-M-23 with a P167T substitution in the active-site omega loop associated with ceftazidime resistance. J. Antimicrob. Chemother. 2004, 54, 406-409. [CrossRef]

31. Pai, H.; Lyu, S.; Lee, J.H.; Kim, J.; Kwon, Y.; Kim, J.W.; Choe, K.W. Survey of extended-spectrum beta-lactamases in clinical isolates of Escherichia coli and Klebsiella pneumoniae: Prevalence of TEM-52 in Korea. J. Clin. Microbiol. 1999, 37, 1758-1763. [CrossRef] [PubMed]

32. Yang, J.L.; Wang, M.S.; Cheng, A.C.; Pan, K.C.; Li, C.F.; Deng, S.X. A simple and rapid method for extracting bacterial DNA from intestinal microflora for ERIC-PCR detection. World J. Gastroenterol. 2008, 14, 2872-2876. [CrossRef] [PubMed] 